\title{
On the canalization of seismic energy $\left({ }^{*}\right)$
}

\author{
P. CAIOI
}

Ricevuto il 30 Luglio 1964

SUmmary. - The paper shows how the velocities of the channel waves $P_{a}$ and $S_{a}$, as thus far calculated, are apparent velocities. From such apparent values it is easy to calculate the real velocities, which coincide with the minimum velocity of longitudinal and transversal waves, calculated by B. Gutenberg and by Miss I. Jehmam for the astenosphere.

The canalization of seismic energy is a general phenomenon which, in the case of strong earthquakes with focus ca. $100 \mathrm{~km}$ deep, may involve not only the astenosphere, but also the earth crust channels. Important examples are alleged.

The paper finally shows that also the energy developped by deep earthquakes (600 km deep and more) undergoes remarkable canalization. However, this eoncerns to a significant extent only the astenosphere.

Rrassunto. - La nota mostra come le velocita delle onde canalizzate $T_{a}$ ed $S_{a}$, finora calcolate, siano velocita apparenti. I ai valori ottenuti per queste ultime, e facile calcolare le velocita reali, le quali coincidono con la velocita minima delle onde longitudinali e trasversali calcolate da $B$. Gutenberg e Miss I. Jehmamn, per l'astenosfera.

La canalizzazione dell'energia sismica e un fenomeno generale che, nel caso di forti terremoti con profondita ipocentrale di $100 \mathrm{~km}$ ca., puo interessare non solo l'astenosfera ma anche i canali della crosta terrestre: a questo proposito nel testo si riportano notevoli esempi.

La nota, infine, mostra che anche l'energia sviluppata da terremoti a profondita di $600 \mathrm{~km}$ ed oltre, subisce una notevole canalizzazione: ad ogni modo, detta canalizzazione interessa in maniera significativa solo l'astenosfera.

$\left(^{*}\right)$ Presentato al "Symposium on Theory and Computers", organizzato a Mosca dall'“ Upper Mantle Committee" dal 15 al 21 Maggio 1964. 
Canalized waves were the first discussed in 1953, when I male a communication to the Accademia dei Lincei on the existence of longitudinal and transversal waves guided by the astenosphere $\left.{ }^{1}\right)$. I indicated such waves by $P_{a}$ and $S_{a}$, Gutenberg, who soon confirmed their existence and my interpretation, suggested the symbols $P_{a}$ and $S_{a}$, changing into a small letter the capital $A$, initial of "astenosphere".

It is well known how, in my interpretation and in Gutenberg's, the proper physical condition for the diffusion of such waves is the existence of a wide low-velocity layer beneath the earth crust, which has been named by many "astenosphere". Gutenberg devoted many periods of his hard-working life to the study of such zone, after 1926. The last study was carried out before his death (which was, as it is well know, on January 5 th, 1960). In this paper, at page 351, the velocity values for longitudinal and transversal waves - at intervals of $10 \mathrm{~km}$ each - for increasing depth, from 40 to $400 \mathrm{~km}$ are reported.

According to Gutenberg's opinion, the minimum velocity for longitudinal waves $(7.8 \mathrm{~km} / \mathrm{sec}$, at other times he had indicated it as $7.85-7.9$ $\mathrm{km} / \mathrm{sec}$ ) should be found at a depth of 80-100 km, while the minimum velocity for transversal waves $(4.4 \mathrm{~km} / \mathrm{sec})$ should be found at a depht of cal. $150 \mathrm{~km}\left({ }^{2}\right)$.

The real waves velocities shall therefore be found within this range $(7.9 ; 4.4 \mathrm{~km} / \mathrm{sec})$ respectively for $P_{a}$ and $S_{a}$ waves. Such were indeed, the average values which $I$ found for the velocity of these waves in my first work on the subject ${ }^{1}$ ).

However, later on, those who concerned themselves with these waves calculated higher values for their velocity; this started with Ewing and Press who studied them in 1954 separately from Caloi.

Of course, I shall not report here all the results obtained by the various scientists. I shall only mention two of the most accurate among such studies. Magnitsky and Khorosheva $\left(^{3}\right)$ processed the $P_{a}$ and $S_{a}$ waves's recordings taken by Russian scismic stations, drawn from the study of 9 earthquakes, for epicentral distances between $22^{\circ}$ and $150^{\circ}$. The two Russian scientists found dromochrones for the $P_{a}$ and $S_{a}$ waves to be straight lines of equations

$$
\begin{aligned}
& t_{(\min )}=0,9558+0,2205 \Delta^{\circ} \quad P_{a} \\
& t_{(m i n)}=0,3780+0,4180 \Delta^{\circ} \quad S_{a} .
\end{aligned}
$$

From these, we may draw the velocities of 8.3 and $4.4 \mathrm{~km} / \mathrm{sec}$, respectively for the $P_{a}$ and $S_{a}$. 
R. R. Guidroz and R. G. Baker, in a chapter on "Channel Waves" (") give the following results of $P_{a}$ and $S_{a}$ waves transfer times:

$$
\begin{aligned}
& t_{(\text {min })}=0,85+0,223 \Delta_{0} \\
& t_{(\text {min })}=0,96+0,403 \Delta^{\circ}
\end{aligned}
$$

whenee we may draw for $P_{a}$ and $S_{a}$ respectively the velocities of 8.31 . $\mathrm{km} / \mathrm{sec}$ and $4,59 \mathrm{~km} / \mathrm{sec}$ (Fig. 1).

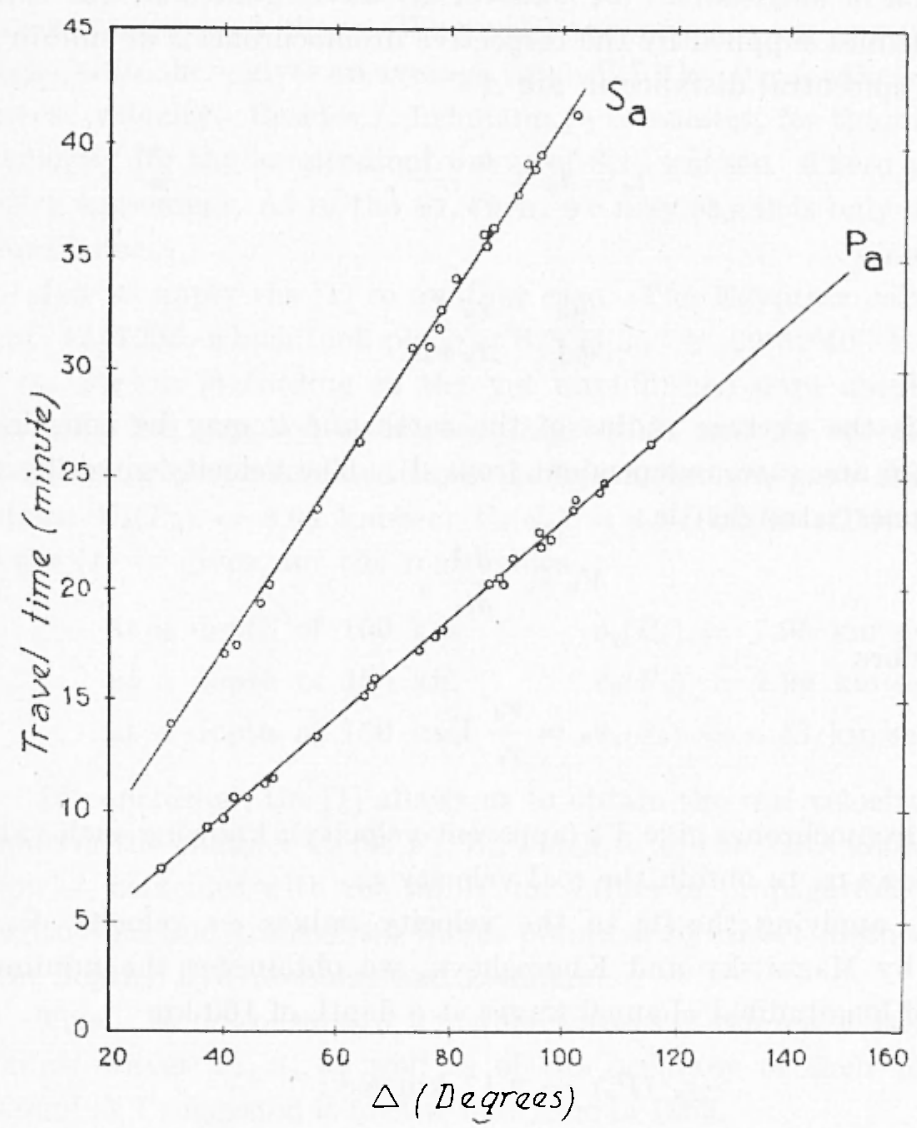

Fig. 1 - Observed $P_{a}$ and $S_{a}$ travel times (according to Guidroz and Baker).

On the other hand, this is the average value obtained for the velocity of these waves also in the study of recordings regarding a single earthquake. There seems therefore to exist a remarkable difference between the results achieved by Gutenberg - with methods connected with the propagation of body waves - for the minimum velocities in the astenosphere, and those supplied by the study of channel waves. 
But are the velocities drawn directly from the arrival time curves of the $P_{a}$ and $s_{a}$ waves really the true velocities? It is easy to prove that they actually are only apparent velocities. In fact, if we indicate by $r_{a}$ the radius of the astenosphere (in its section characterized by the minimum velocity) and by $v_{a}$ the real propagation velocity on the cireumference of such radius, if $t_{a}$ are the times obtained on the surface for the propagation of longitudinal (or transversal) waves guided by the asthenosphere (times supplied by the respective dromochrones), we obtain $\left(^{5}\right)$, being the epicentral distance in are $A$

$$
t_{a}=t_{o}+\frac{t_{a}}{r_{o}} \frac{\Lambda}{v_{a}}
$$

and therefore

$$
\frac{d t_{a}}{d\lrcorner}-\frac{r_{a}}{r_{0}} \frac{1}{v_{a}}
$$

where $r_{0}$ is the average radius of the earth and $t_{0}$ may be considered constant (in any case, independent from $A$ ). The velocity given by the dromochrones (straight) is

$$
V_{a}=\frac{d 1}{d t_{a}}
$$

and therefore

$$
v_{a}=\frac{r_{a}}{r_{o}} V_{a}
$$

The dromochrones give $V_{n}$ (apparent velocity); knowing such value, the [1] allows us to obtain the real velocity $v_{a}$.

Then, applying the [1] to the velocity values - velocity $V_{a}$ obtained by Magnitsky and Khorosheva, we obtain for the minimum velocity of longitudinal chamnel waves at a depth of $100 \mathrm{~km}$

$$
v_{a}\left(P_{a}\right)=8,17 \mathrm{~km} / \mathrm{sec} \text {; }
$$

for the same minimum velocities at $150 \mathrm{~km}$ depth

$$
v_{a}\left(P_{a}\right)=8,1 \mathrm{~km} / \mathrm{sec} .
$$

By calculating the real value of the transversal waves' velocity at $150 \mathrm{~km}$ depth, we obtain, on the basis of the apparent velocity obtained by the Russian scientists:

$$
v_{a}\left(S_{a}\right)=4,365 \mathrm{~km} / \mathrm{sec} .
$$


Applying the [1] to the values calculated by Guidroz and Baker, for a minimum velocity at $150 \mathrm{~km}$ depth, we obtain

$$
\begin{aligned}
& v_{a}\left(P_{a}\right)=8,1 \mathrm{~km} / \mathrm{sec}, \\
& v_{a}\left(S_{a}\right)=4,48 \mathrm{~km} / \mathrm{sec} .
\end{aligned}
$$

The velocity of the $P_{a}$, given lately by Gutenberg, is slightly inferior to the one reported above. We must howerer point ont how, in previous works, Gutenbereg gives an arelage value of $7,9 \mathrm{~km} / \mathrm{sec}$ for the longiturlinal waves' velocity. Besides I. Iethmann $\left({ }^{6}\right)$ calculates, for the same depth, a velocity for the longitudinal waves of $8,12 \mathrm{~km} / \mathrm{sec}$. There could be no better agreement. As to the $S_{a}$, then, we may say it is only a matter of coincidence.

Let us apply the [1] to another "ase. The Egrptian arthquake of Sept. 12, 1955, which took place at $32^{\circ} 24^{\prime 2} 25^{\prime \prime} \mathrm{N}, 29^{\circ} 52^{\prime} 40^{\prime \prime}$ E at a depth of a. $25 \mathrm{~km}$ (aceording to the yet umpublished data obtained by $\mathrm{T}$. Mareelli), hats supplied clear recordings of $P_{a}$ and $S_{a}$ wares. The apparent velocities, calculated from the dromochrones, gave the following values: $V_{a}\left(P_{a}\right)=8.08 \mathrm{~km} / \mathrm{sec} ; V_{a}\left(S_{a}\right)=4.54 \mathrm{~km} / \mathrm{sec}$. The application of the $[1]$ - gives, for the real values:

$$
\begin{array}{ll}
\text { at a depth of } 100 \mathrm{~km} & v_{a}\left(P_{a}\right)=7.95 \mathrm{~km} / \mathrm{sec} \\
\text { at a depth of } 150 \mathrm{~km} & v_{a}\left(P_{a}\right)=7.90 \mathrm{~km} / \mathrm{sec} \\
\text { at a depth of } 150 \mathrm{~km} & v_{a}\left(S_{a}\right)=4.43 \mathrm{~km} / \mathrm{sec}
\end{array}
$$

In conclusion, the [1] allows us to obtain the real velocity of propatgation of the channel wares $P_{a}, S_{a}$ which - in the cases under comsideration - coincides with the minimmm values of propagation relocity of longitudinal and transrelsal waves obtained by direct methods (for the same depths) by Gutembergand Tehmamn.

This is to be considered a further witness of the real existence of the channel waves $P_{a}, s_{a}$ as well as of the accuracy of their propagation system, as I suggested it for the first time in 1953.

2. - In my opinion, the phenomenon of canalization or guide of seismie encregy has not thus far received all the attention it deserves. Such phenomenon plays a role of primary importance in the acequisition of new knowledge on the physical and chemical aspects of the upper mantle. This may be achieved only after a careful study of the mantle itself, which is much wider than we are likely to believe so fal. This is, howerer, only my own opinion. 


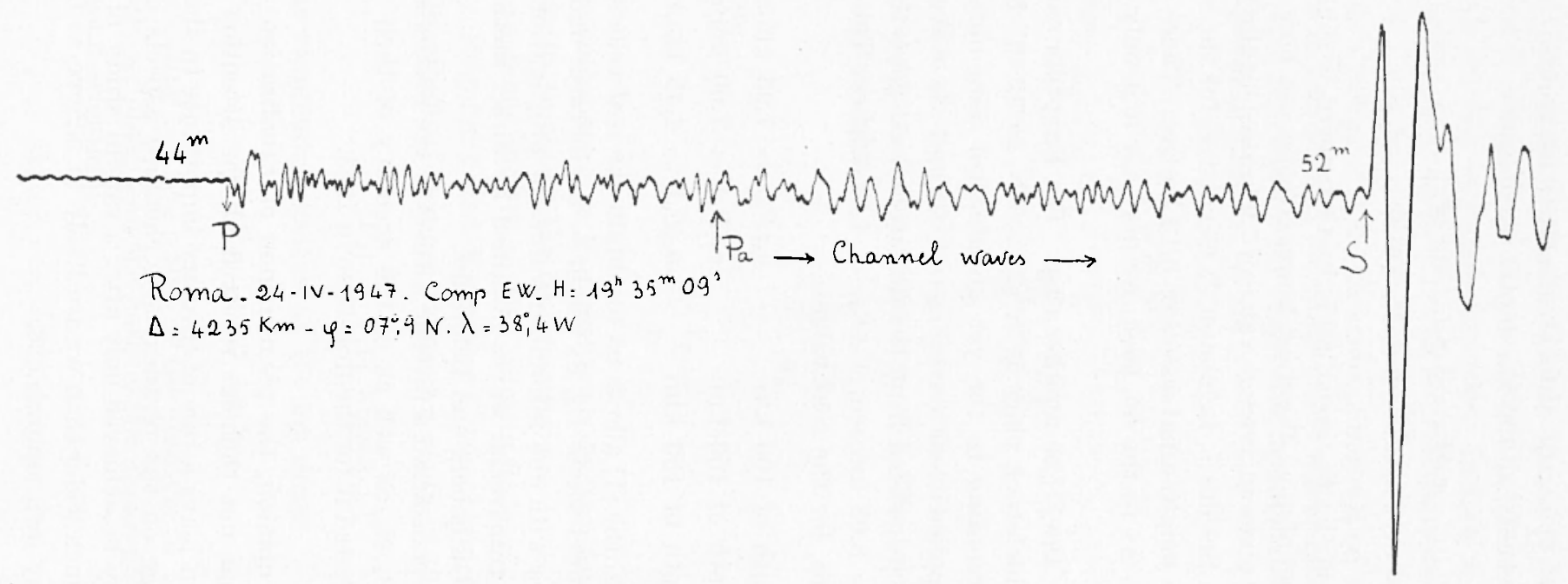

Fig. 2 - Chamnel waves on mixed path (atlantic and continental). 
Being all conditions equal, the canalization concerns specifically the stratifications of che earth crust or the asthenosphere, depending upon whether the earthquake has its origin in the crust or ac depths in the range of a few hundreds of $\mathrm{km}$. In the case of earthquakes at intermediate depths, of sufficient intensity, all the upper section of the mantle, from the astenosphere up to the superficial crust stratification becomes the seat of canalization.

Jet us consider the following examples.

Ewing, Press, Bath, Gutenberg ... have already shown that the surface stratification of the earth crust conducts transversal wares $\left(L_{g}\right.$, $L_{R}$ ), though their propagation system be variously interpreted (multiples reflections or high-node surface waves according to Ewing, Press, Oliver...; zonal canalization with velocity flexion according to Gutenberg, Bath...).

These types of waves, having a rather short period, do not secm to propagate at great distances. In this very brief exposition, I shall only refer to waves having a rather long period (from ca. 10 seconds upwards).

What I want to show is that such phenomenon is not limited to the astenospliere. See the example supplied by the recordings caused in mediumperiod seismographs (i.e. the Galitzin I.N.G. in Rome) by the earthqualie of the submersed dorsal in the Atlantic Ocean, on April 24, 1947 (Fig. 2). It shows very clearly how, beside the $P_{a}$, there are other phases which precede the $S_{a}$ waves and samnot be ascribed to multiple reflections, but only to a part of the seismic energy captured and canalized by the earth crust canals.

In this particular case, as the earthquake has an Atlantic origin, the eanalization is initially limited to the astenosplere, but we must believe that it has later on interested also the continental socle area, then extending also to the three continental layers.

But the canalization takes relevant proportions with earthquakes having their origin at about $100 \mathrm{~km}$ depth. An extremely interesting witness to this regard is the earthquake of July 25, 1960. See the seismogram reproduced in Fig. 3. It has been recorded by a long-period pendulum (ca. 90 sec.) operating still experimentally at the new seismic station of I'Aquila. This earthquake - (these are its characteristic date: $a=$ $54 \mathrm{oN} . \lambda=159 \mathrm{oE}, H=11.12 .00, h=100 \mathrm{~km}$ ea., $M=7$-Pasadena, Rome) was about $100 \mathrm{lim}$ deep. Notice the long uninterrupted sequence of canalized waves from the asthenosphere and from the layers of the earth crust, both longitudinal and transversal. The seismogram may be divided into four separate sections: longitudinal body waves, direct and reflected, 
having short period (I); channel waves from the astenosphere and the earth erust, with a definitely longer period (II); transversal body waves direct and reflected (III), and transversal channel waves (IV). The last are to be considered the transversal analogues to the chammel longitudinal waves of the II section (except the Lowe waves, which are recorded among them).

3. - In the case of deep earthquakes (focused at more than $350 \mathrm{~km}$ from the external surface according to Gutenberg's division), is there a possibility of canalization? If so, which zones does it interest?

I have sturdierd, with this purpose in mind, the strong deep earthquake of the Japan Sea, which took place at $40^{\circ}, 0 \mathrm{~N}-129^{\circ}, 7 \mathrm{E}$, on October $8^{\text {th }}, 1960$, — with an origin time $H=05.53 .01,1$ - at a depth of ca. $600 \mathrm{~km},-$ according to the U.S.G.G.S. Its magnitude was evaluated, at Pasadena, between 6.5 and 7.5 .

Limiting the exam, for the present, to the $S_{n}$ waves, I noticed in the about 50 scismograms in my posscssion, and spccially anong the recordings taken with medium and long-period seismograms, consp)icuous examples of transversal chamnel waves. After resolving their dromochrones with the method of the minimum squares I obtained

$$
V_{n}\left(S_{a}\right)=t, 615 \mathrm{~km} / \mathrm{sec}
$$

whence, by means of the [1],

$$
v_{a}\left(S_{a}\right)=4,41 \mathrm{~km} / \mathrm{sec} .
$$

There are, therefore, channel waves from the astenosphere.

There are among the most evident phases of the seismograms I rhecked (Figg. $4 a-t b$ ); indeed, in many instances, the $s_{a}$ appears to be the most remarkable phase in the whole seismogram (Figg. te-5). This proves that upucards canalization is not only possible, but it has also the power of conveying a remarkable part of the seismic energy into the astenosphere.

The $S_{a}$ vertical component is always very strong (Figg. $4 c-t d$ ).

In the earthquake under consideration, no noticeable examples of canalization from the earth crust have appeared.

Finally, the canalization appears to be a general phenomenon, which plays a remarkable role in the propagation of seismic energy. It may concern both the earth crust stratifications and the astenosphere. It is most effective in correspondance of strong earthquakes originated in the astenosphere, that is, it can interest at the same time the clust eamals beside the astenosphere. 


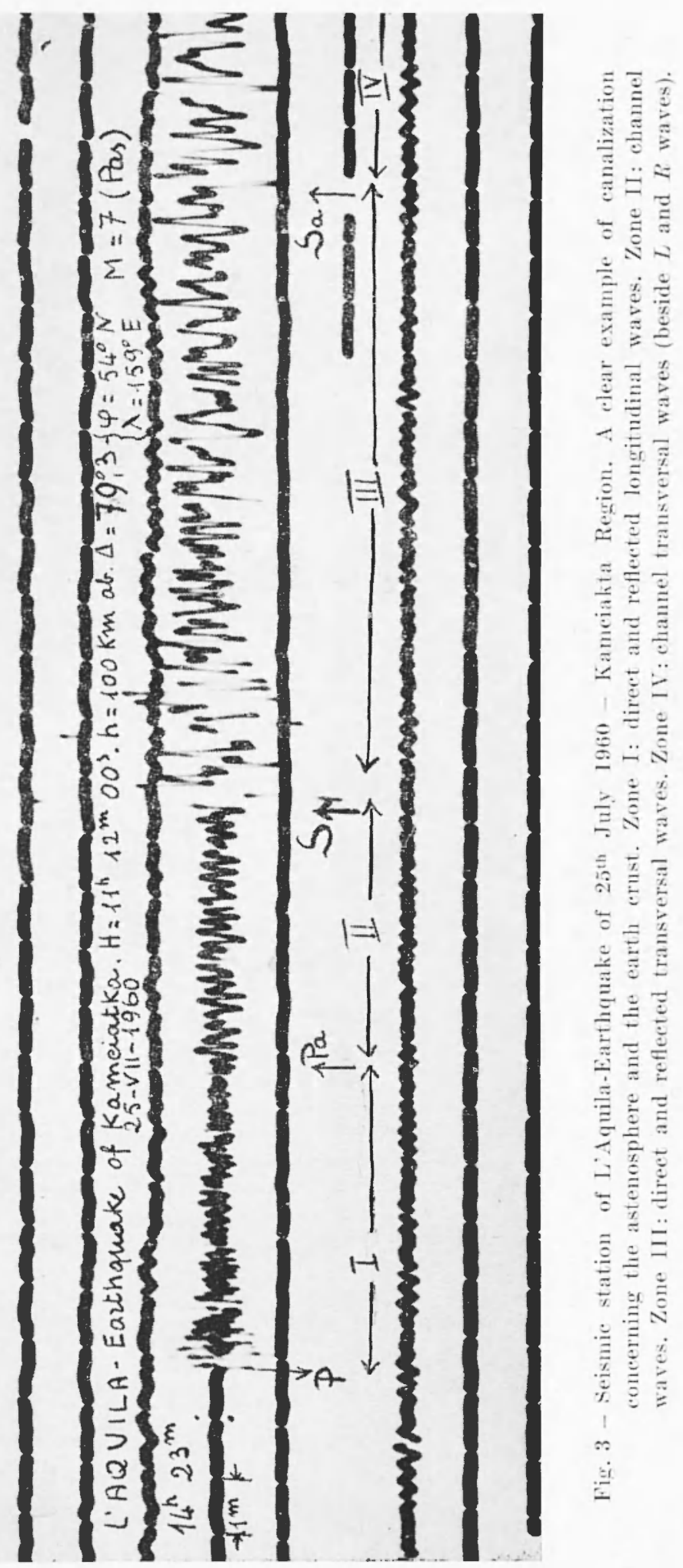


T'. ('Al,OI

ROMA-Comp.vert. Whin. Earthawake of Japam bea. 8-x-1960. H=05"53"01'

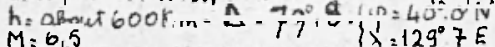

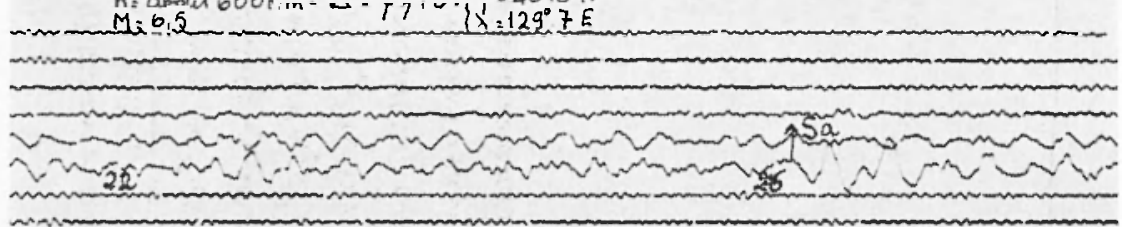

F'ig. ta -- Records obtained in the seismice station of Rome ... Wilip vert. component . Larthqualie of sth October 1960 . Jalpan seal.

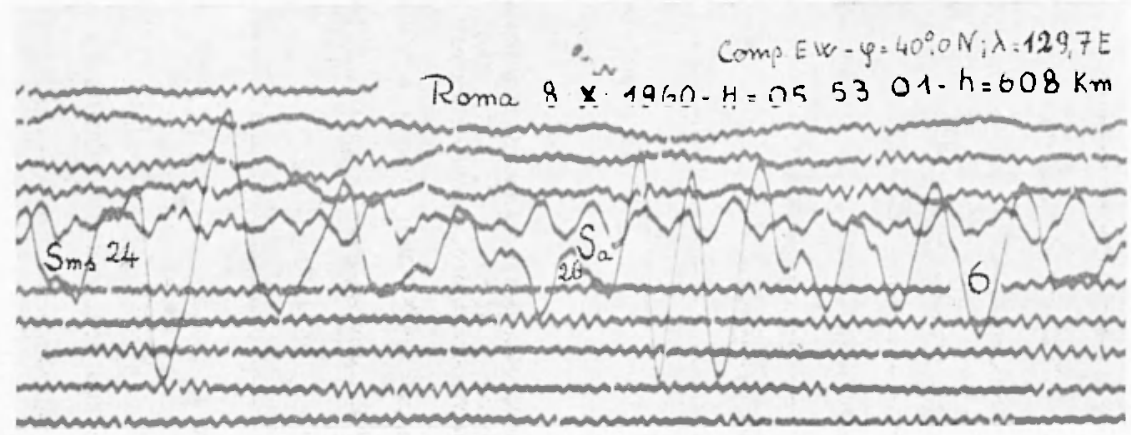

Fig. $4 b$ - E-W component - The same earthquake. 

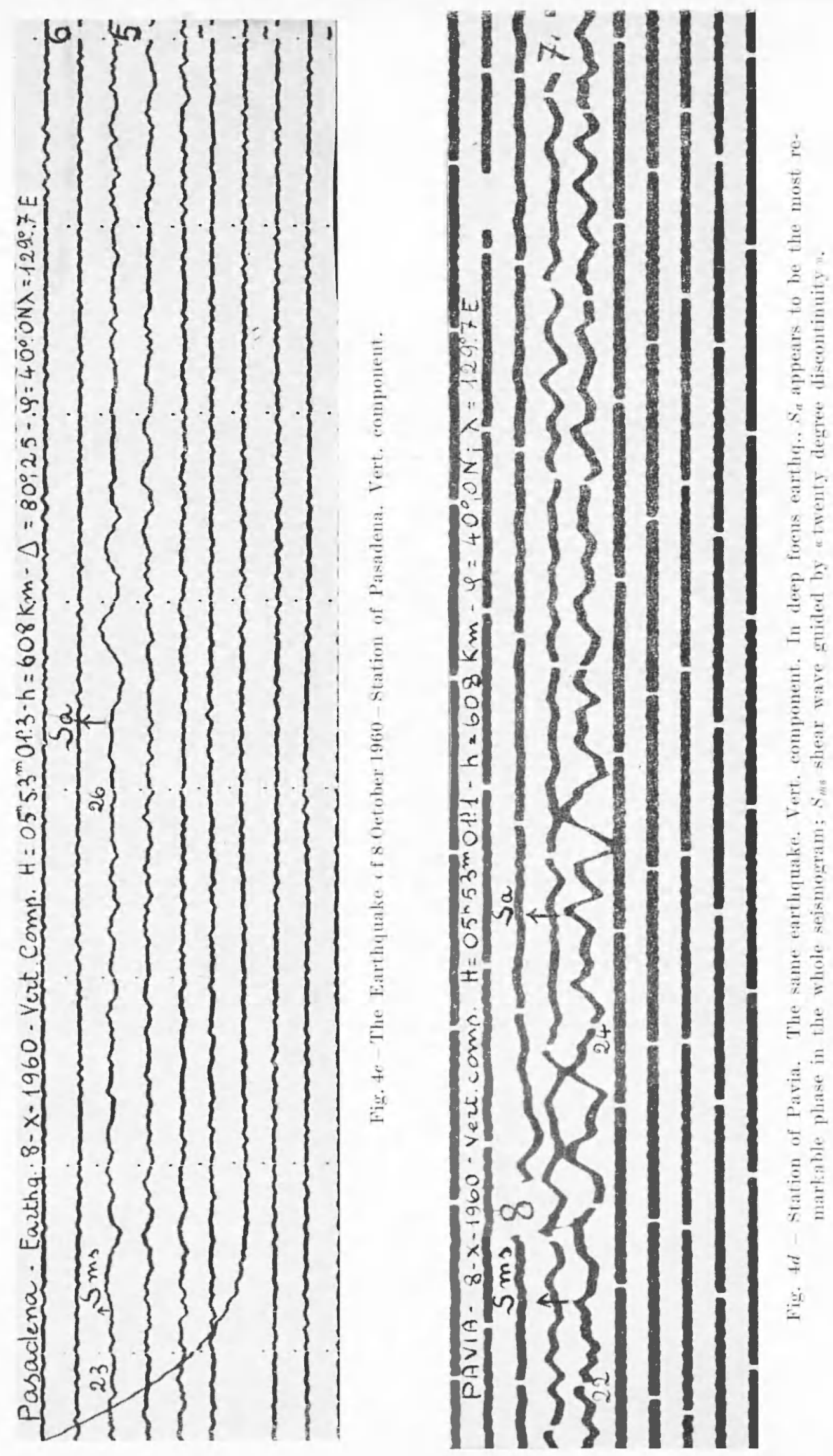


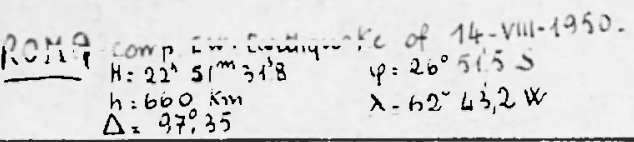

l'ig. 5- Record obtained in the seismie station of Rome- $\mathrm{E}$ IV component Liathiquake of $14^{\text {th }}$ Augrust 1950. 
In the case of deep focus earthquakes, canalization is especially remarkable only in the astenosphere.

\section{RECTIFICATION.}

In the last years some authors, while stulying the camalization of the seismic waves (Bath, Vesanen, Anderson) have attributed the discovery of this phenomenon to $B$. Gutenberg.

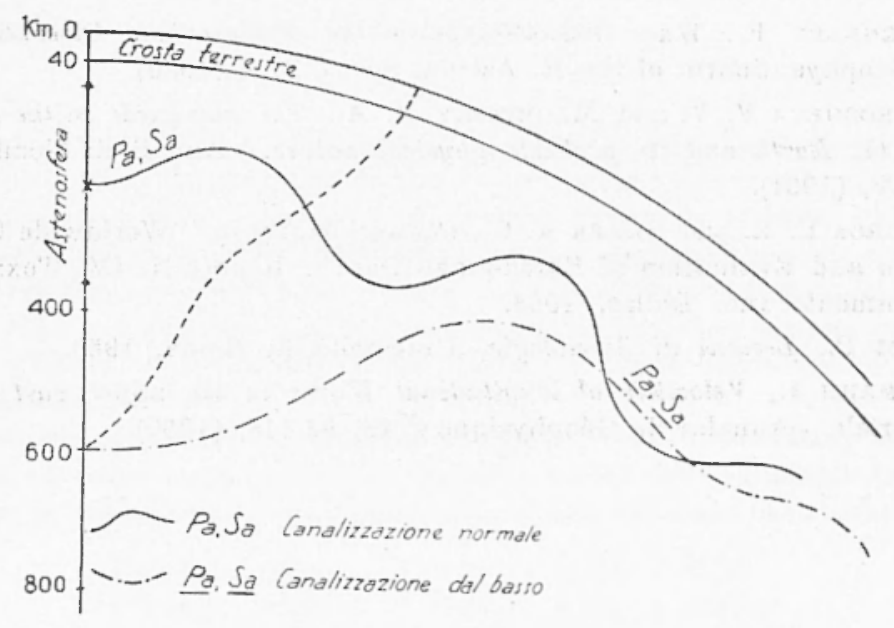

Fig. 6 - Examples of normal and deep focus canalization.

I think that a rectification is necessary. The priority of this discovery is of Caloi, who announced this phenomenon for the first time in 1953. Perhaps the cause of that confusion is due to the eaption of Figure 4-7 (a), on pg. 87 of the "Physics of the Earth's Interior" ...-published by Gutenberg in 1959 - where the Author, (quoting the scheme of the canalization, writes in brackets that this scheme has been suggested by Gutenberg (1954) and Caloi (1954).

Of course it is an oversight; in fact that scheme has been alrealy pointed out by Caloi in the first work on this subject, on por. 353 of the "Rendiconti dell'Aecatemia Nazionale dei Lincei" (Classe di Scienze fis., mat. e nat.) series VIII, vol. XV, numb. 6, 1953.

By the way that clearly appears in the same test of the book by Gutenberg. Moreover the same Gutenbere ("The asthenesphere lowvelocity layer" "Annali di Grofisica ", vol. XII, n. 4, 1959), on pg. 413, 
says what follows: "A very important discovery was made by Caloi $(1953,1954)$ when he observed and explained correctly two new phases . . "

The note of Gutenberg on the canalization in fact came after the paper of Caloi and appeared for the first time in 1954.

\section{REFERENCES}

(') CaroI, Onde longitudinali e trasversali guidate dall'astenosfera. "Rend. Accademia Naz. dei Lincei ", serie VIII, vol. XV, fasc. 6, 1953.

${ }^{(2)}$ Gutenserr; B., Ware Velocities below the Mohorovicic Discontinuity. "Geophys. Journ. of the R. Astron. Soc. ", 2, 4, (1959).

(3) Knorosineva V. V. and Marinitsky V. A., The waveguide in the mantle of the Earth and its probable physical nature. "Annali di Geofisica", XIV, (1961).

(4) GUIDroz R. R. and BAKER R. G., Channel Waves in "Worldwide Collection and Evaluation of Earthquake Data ". Report N. IV, Texas Instruments Ine. Dallas, 1963.

(5) Calor P., Lezioni di Sismologia, Universita di Roma, 1960.

${ }^{(6)}$ LEHMANx I., Velocities of longitudinal Waves in the upper part of the Earth's. "Annales de Geophysique ", 15, 93-118, (1959). 